\title{
EDMUND A. PARKES IN THE DEVELOPMENT OF HYGIENE
}

\author{
GEORGE ROSEN, M.D., Ph.D. \\ Yale University, New Haven, Connecticut
}

IN 1867, William F. Thoms, a New York physician, published a study of the tenement houses in the city, with specific attention to the size of the area on which individual buildings were erected, the cubic feet of air space available per person within them, and the problem of ventilation in relation to the occurrence of various diseases. In the first paragraph of his paper, Thoms noted that in its preparation he had consulted " the most practical works on hygiene ", naming specifically " Dr. Parkes' Manual on Practical Hygiene $^{1}$ ". The book to which Thoms referred had appeared in 1864, and was the work of Edmund Alexander Parkes (1819-1876) then professor of hygiene at the Army Medical School, a position to which he had been appointed in 1860 on the establishment of that institution ${ }^{2}$. To judge from the tone in which Thomas refers to this book, it had already become an authoritative source soon after publication. In fact, it continued to be "the most important English treatise on hygiene" for the remainder of the century, even though after Parkes' death in 1876 it was edited by others, among them in 1883 F. S. B. de Chaumont, his successor at the Army Medical School, and in 1891 J. Lane Notter ${ }^{3}$.

Although initially intended for medical officers in the army, Parkes' work was expanded in successive editions to deal with various aspects of hygiene in civilian as well as military life. As the first comprehensive organized treatment in English of the available knowledge on the preservation of health and the prevention of disease, it exerted an important influence on those concerned with community health. Sir Arthur Newsholme's expression of his indebtedness to the Manual of Practical Hygiene exemplifies this impact on a whole generation. Commenting retrospectively in 1935, he observed that it had prepared " others, like myself, for their public health work" ".

The characteristic qualities of this text, particularly as it appeared during its author's lifetime, reflect his experiences, interests and personality. Educated at Christ's Hospital, London, Parkes obtained his medical training at the University College and Hospital, graduating M.B. in 1841. While still a student, he was introduced to experimental investigation by working in the laboratory of his uncle, Anthony Todd Thomson, professor of materia medica, where he acquired an interest in the scientific study of medical problems as well as considerable manual dexterity ${ }^{5}$. Parkes' ability and industry appear to have attracted the attention of his teachers. Charles J. B. Williams, professor of medicine at University College, later wrote in his memoirs that he was "a most attentive student at my lectures; but did not compete for my medals, being much engaged with his relative, Dr. Anthony Todd Thomson". During the summer of 1840, however, when Williams performed some experiments " on the contractility and sensibility of the lungs and air tubes", Parkes was one of his student assistants ${ }^{6}$.

Shortly after his graduation, Parkes, then 22, joined the army as an assistant surgeon. Assigned to the 84th (York and Lancaster) Regiment, he served in India for somewhat less than three years, retiring from the army in September 1845. Experience with tropical 
diseases, particularly cholera, dysentery (probably amebic and bacillary in origin), and hepatitis provided material for several publications following his return to England and entry into private practice. In 1846, Parkes received his M.D. at the University of London with a thesis entitled Remarks on the Dysentery and Hepatitis of India. During his period of service he had plenty of opportunity to study dysentery and its complications, clinically and at necropsy; and his book reveals starkly the rudimentary state of knowledge concerning the disease midway in the 19th century. Despite Parkes' objective clinical descriptions and his precise presentation of autopsy findings, it is impossible even to estimate how many of his dysentery cases were bacillary and how many amebic. The association of dysentery with hepatic abscess was recognized, but which was cause or effect remained a puzzle. At the same time, his comments on the modes of investigation to be employed in clarifying this situation intimate the course Parkes was to take. Furthermore, throughout his monograph there is an emphasis on the need for scientific investigation as a means of solving practical problems in health and disease.

"To attempt to explain the pathology of dysentery now", he wrote, "would be as premature as it would be to explain that of a fever ... I am not of the opinion of those who believe that the old paths of investigation - the study of symptoms and of post-mortem appearances-are now exhausted. If this be the case, how is it that the morbid anatomy of dysentery has not, to my knowledge, hitherto been fully described? How is it that in cholera, in spite of ample opportunities, every new writer discovers something that his predecessors have overlooked? How is it that the most important renal diseases have only been described within the last few years? Because new modes of investigation have been opened to us, why should we give up the old ones?

"I estimate most highly the value of microscopic investigation, and of chemical analysis, in the study of diseases; but can these be applied yet with any degree of safety? The chemical analysis of organic fluids is most difficult, and partial or imperfect examination is useless. The recondite operations of nature have not yet been imitated in the laboratory of the chemist, and the condition of the disordered secretions during disease presents an immense subject for investigation, which can hardly be said to be as yet even touched ${ }^{7} "$.

Parkes' emphasis on the importance of the scientific investigation of intermediate metabolism and its products in health and disease is a basic theme which recurs in many of his later contributions. This characteristic is specifically illustrated by his endeavour in the dissertation on dysentery to relate the quantity of urea excreted by the kidneys to the severity of the pathological process in supperative hepatitis ${ }^{8}$. This early hypothesis foreshadowed a focus of interest to which Parkes devoted an increasing amount of attention in subsequent years, leading to the publication in 1860 of The Composition of the Urine in Health and Disease, and under the Action of Remedies.

Parkes' scientific research on this subject led to even more important results presented in three papers in the Proceedings of the Royal Society (two in 1867 and one in 1871,) dealing with the effects of diet and exercise on the elimination of nitrogen. These studies were summed up in the Croonian Lectures delivered before the Royal College of Physicians early in $1871^{\circ}$. Based on experiments and observations made independently, Parkes confirmed the findings of Adolf Fick (1829-1901) and Johannes Wislicenus 
(1835-1902) in 1865 as a result of their ascent of the Faulhorn, an Alpine peak, near Grindelwald in Switzerland. Contrary to the view of Justus Liebig; they found that energy for muscular contraction did not come chiefly from the combustion of protein, and that muscular activity did not result in increased nitrogen excretion.

The experiments reported by Parkes were made in the 1860 s after his appointment at the Army Medical School, and were contemporary with the investigations of Max Pettenkofer and Carl Voit in Munich, who arrived at similar conclusions. Parkes was fully abreast of current work in the physiology of muscular activity and the metabolism of nutrients, referring often to the findings of Carl Voit, J. Ranke, Elie Cyon, his countryman Edward Smith and others. For his investigations, he used human subjects, measuring their ingesta and analyzing their excreta chemically in the laboratory. This is, in fact, one of Parkes' major contributions to the development of hygiene, the great value and emphasis placed on the utility of experimental and laboratory methods in the investigation of health problems.

Like Pettenkofer, with whom he may well be compared, Parkes was not an ivorytower scientist; he was as much concerned with the practical application of the results of his researches as with their scientific consequences. As with his German contemporary, this attitude was the product of a broad and varied experience. Parkes had an extensive clinical background based not only on his private practice, but even more on experience derived from his activities as professor of clinical medicine at University College, and as a physician to the University College Hospital, posts to which he had been elected in 1849. During the following decade, in addition to his writings on cholera, dysentery and other gastro-intestinal disorders, his contributions to the medical literature dealt with diseases of the heart, pyrexia, skin conditions, as well as medical education. Moreover, from 1852 to 1855, he edited the British and Foreign Medico-Chirurgical Review. That year, during the Crimean War, Parkes was sent by the British government to Turkey for the purpose of establishing and supervising a large civilian hospital so as to relieve the pressure on the hospitals at Scutari. After selecting a site at Renkioi on the Asian side of the Dardanelles, he carried out his mission, remaining there until the end of the War in 1856. As a result, when Parkes became professor of hygiene at the newly created Army Medical School, upon which he had been consulted by Sidney Herbert, secretary of state for war, he was exceedingly well equipped to deal with his new responsibilities as a teacher, scientific investigator and adviser to the government.

As a professor of hygiene, Parkes addressed himself to problems of medical education, a subject on which he presented a plan in the Lancet in 1868, based on the system of instruction he had organized at the Army Medical School ${ }^{10}$. It was during this period that Parkes was working on his Manual and carrying out his experiments on the relation between muscular activity and the metabolism of nitrogenous compounds in the body. The text was one element in his endeavour to create a science of military hygiene, and to make this knowledge available to medical officers in the army, particularly since medical officers had been given powers to advise commanding officers on all matters pertaining to the health of troops ${ }^{11}$. At the same time, Parkes was engaged in inquiries with implications for both military and civilian hygiene. Between 1870 and 1874 , he carried out a series of experiments on the effects of alcohol and other stimulants on the human body ${ }^{12}$.

Parkes was frequently called upon by governmental agencies to assist in specific 
investigations, as exemplified by his short association with John Simon when the latter was Medical Officer to the Privy Council. Cholera appeared in Southampton and its environs in September-October, 1865, and again in July-August, 1866, and Simon requested Parkes to investigate the outbreaks. The reports prepared by Parkes were published in the Eighth and Ninth Reports of the Medical Officer of the Privy Council $(1866,1876)^{13}$. His methodology and logical analysis of the collected data reveal that Parkes was an excellent epidemiologist. From his investigation of 1866, he concluded that there was no evidence to link the epidemic causally with " peculiar atmospheric or unknown epidemic conditions. There was no evidence of such epidemic influence in any increased illness, diarrhoeal or otherwise, before the outburst, and there was nothing unusual in the common meteorological conditions.

" I believe, however, that the outburst is capable of a satisfactory explanation, provided only the proviso be granted that the intestinal discharges of cholera are capable of propagating the disease at once, or at a certain period of decomposition "14. According to Parkes, intestinal discharges of cholera patients entered the sewerage system and were distributed throughout Southampton. Owing to defects in the sewerage system, gasses produced by decomposing fecal matter pervaded houses and produced the disease in susceptible individuals.

Theories of this type which recognize the communicability of disease through intestinal discharges, but could not explain the nature of the transmissable material, help to place Parkes and his work in a specific historical context. This is made even more explicit by noting that Parkes died on March 15, 1876, and that at the end of April, 1876, Robert Koch demonstrated the life history of the anthrax bacillus, thus inaugurating the microbiological period in the history of hygiene. Parkes belongs to the pre-bacteriological era. Like his contemporaries, he was chiefly concerned with the impact of environmental factors such as air, food and water on health, and it was in the investigation of such problems that he made some of his most important contributions. From the first Parkes associated the chemical laboratory and the physiological experiment with his endeavour to create a science of hygiene. This is well exemplified by his studies on the metabolism of nitrogenous substances in the animal organism. Not only did he confirm the findings of Fick and Wislicenus but as his contemporaries recognized he opened up an area of investigation which was to be of incalculable significance for the future of medicine, namely intermediate metabolism

Commenting on his Croonian Lectures, an editorial in the Lancet noted that they led " to the very mysteries of life ... In what part of the body takes place the mysterious transformation of albumen into urea? What are the steps of the process of transformation? What is the connection between the integrity of this process and the maintenance of health ? ${ }^{15 "}$ These and related questions were to be the subject of investigations in metabolism during the later 19th century and throughout the present century. From this viewpoint, Edmund Alexander Parkes was a pioneer in the application of scientific methods and techniques to the creation of a physiological hygiene which would provide a firm foundation for the prevention of disease and the promotion of health. Even with the limited means available to him, Parkes was able to make positive contributions upon which others could build, and to open up problems which those who came after him would explore and elucidate. 


\section{BIBLIOGRAPHY}

1 W. F. Thoms: Tenant Houses. Their Ground Area, Cubic feet of Air Space and Ventilation. Trans. N.Y. State Med. Soc. (1867). Pp. 299-314 (see P.299).

2 Edmund A. Parkes: A Manual of Practical Hygiene. Prepared Especially for use in the Medical Services of the Army. (1864). John Churchill \& Sons Ltd. London.

3 Fielding H. Garrison: An Introduction to the History of Medicine. (1929). 4th ed. W. B. Saunders, Philadelphia. Pp. 660-661.

In addition to the various English editions, Parkes' Manual was translated into a number of European languages. According to Stanhope Bayne-Jones, 19 editions were published between 1864 and 1900 but he apparently included editions in foreign languages; see Stanhope Bayne-Jones: The Evolution of Preventive Medicine in the United States Army, 1607-1939. (1968). Washington, D.C. P.92.

4 Sir Arthur Newsholme: Fifty Years in Public Health. A Personal Narrative with Comments. The Years Preceding 1909. (1935). George Allen \& Unwin. London. P.70.

5 Anthony Todd Thomson (1778-1894) issued the London Dispensatory in 1824.

- Charles J. Williams: Memoirs of Life and Work. (1884). Smith, Elder \& Co. London. Pp. 146-147, 151.

7 Edmund A. Parkes: Remarks on the Dysentery and Hepatitis of India. (1846). Longman, Brown et al. London. Pp. 135-136.

8 Ibid. P.VIII.

admund A. Parkes: Some Points Connected with the Elimination of Nitrogen from the Human Body. Lancet (1871). Pp. 399-403, 467-472.

See also Proceedings of the Royal Society. (1866-1867). 15, 339-355. Ibid. (1867-1868). 16, 44-59.

10 Edmund A. Parkes: Scheme of Medical Tuition. Lancet (1868). Pp. 441-443, 472-473, 502-504.

11 M. M. Lewis: The Speciality of Army Health: A Brief Historical Review. (1958). Public Health 72, 107-116.

12 Edmund A. Parkes: On the Influence of Brandy on the Bodily Temperature, the Pulse and Respirations of Healthy Men. (1974-1874). Proceedings of the Royal Society 22, 172-190.

Edmund A. Parkes and Cyprian Wollowicz: Experiments on the Effects of Alcohol (ethylalcohol) on the Human Body. Ibid. (1870). 18, 362-393.

Idem: Experiments on the Action of Red Bordeaux Wine (claret) on the Human Body. Ibid. (1871). 19, 73-89.

13 Ninth Report of the Medical Officer of the Privy Council, with Appendix 1866. London (1867). Pp. 244-253 (see P. 251).

14 Royston Lambert: Sir John Simon (1816-1904 and English Social Administration. (1963). MacGibbon and Kee. London. Pp. 353, 378.

C. Fraser Brockington: Public Health in the Nineteenth Century. (1965). E. \& S. Livingstone. London. Pp. 244, 273.

15 Dr. Parkes's Croonian Lectures. Lancet (1871). May 20, Pp. 690-692. 